\title{
O GÊNERO PHYLLANTHUS L. (EUPHORBIACEAE) NA CHAPADA DIAMANTINA, BAHIA, BRASIL ${ }^{1}$
}

\author{
Daniela Santos Carneiro Torres ${ }^{2}$ \\ Inês Cordeiro ${ }^{3}$ \\ Ana Maria Giulietti
}

Recebido em 26/10/200. Aceito em 04/10/2002

\begin{abstract}
RESUMO - (O gênero Phyllanthus L. (Euphorbiaceae) na Chapada Diamantina, Bahia, Brasil). Este trabalho trata do estudo taxonômico das espécies de Phyllanthus L. encontradas na Chapada Diamantina, no Estado da Bahia. Foram reconhecidas 11 espécies: P. amarus Schumach. \& Thonn., P. angustissimus Müll. Arg., P. claussenii Müll. Arg., P. flagelliformis Müll. Arg., P. heteradenius Müll. Arg., P. klotzschianus Müll. Arg., P. niruri L., P. orbiculatus Rich., P. scoparius Müll. Arg., P. spartioides Pax \& K. Hoffm e Phyllanthus sp. O trabalho inclui chave de identificação para as espécies, bem como descrições e ilustrações para cada uma delas.
\end{abstract}

Palavras-chave - Phyllanthus, Euphorbiaceae, Chapada Diamantina, Flora da Bahia

\begin{abstract}
The genus Phyllanthus L. (Euphorbiaceae) in Chapada Diamantina, Bahia, Brazil). This paper presents a taxonomic treatment of the species of Phyllanthus L. from Chapada Diamantina, Bahia. Eleven species are recognized: P. amarus Schumach. \& Thonn., P. angustissimus Müll. Arg., P. claussenii Müll. Arg., P. flagelliformis Müll. Arg., P. heteradenius Müll. Arg., P. klotzschianus Müll. Arg., P. niruri L., P. orbiculatus Rich., P. scoparius Müll. Arg., P. spartioides Pax \& K. Hoffm. and Phyllanthus sp. A key to the species, as well descriptions and illustrations are provided for each one of them.
\end{abstract}

Key words - Phyllanthus, Euphorbiaceae, Chapada Diamantina, Flora da Bahia

\section{Introdução}

A Chapada Diamantina é a parte norte da Cadeia do Espinhaço, no Estado da Bahia. Incluindo 38 Municípios e estendendo-se por
$330 \mathrm{~km}$, a sua porção sul está na região de Ituaçu e Livramento do Brumado, chegando ao norte até Santo Inácio, no Município de Xique-Xique. Toda a região possui relevo muito acidentado, solos pobres em nutrientes e extremamente

1 Parte do trabalho de conclusão de graduação da primeira Autora

2 Departamento de Ciências Biológicas, Universidade Estadual de Feira de Santana, Km 3, BR 116, CEP 44031-460, Feira de Santana, Bahia, Brasil.

3 Instituto de Botânica, C. Postal 4005, CEP 01061-970, São Paulo, SP, Brasil. 
ácidos, com clima mesotérmico, caracterizado por invernos secos e verões brandos e chuvosos (Harley 1995). Variadas formações vegetais são encontradas na Chapada Diamantina, desde campestres até florestais: caatinga, carrasco, cerrado, florestas das encostas das serras, dos grotões e as ciliares. A família Euphorbiaceae está representada em todos estes tipos de vegetação.

Com cerca de 317 gêneros e 8.000 espécies, agrupadas em 49 tribos e 5 subfamílias (Webster 1994), as Euphorbiaceae são predominantemente tropicais, possuindo, entretanto, muitos representantes em áreas temperadas (Webster 1967). Phyllanthus L., com cerca de 750 espécies, está entre os maiores gêneros da família.

Phyllanthus, do grego phyllon (folha) e anthos (flor), em alusão às flores produzidas em ramos que se assemelham a folhas compostas, é gênero em sua maior parte paleotropical, com cerca de 200 espécies distribuídas pelas Américas, principalmente Brasil e Caribe. Cerca de onze espécies atingem latitudes temperadas, estando ausente na Europa e na costa pacífica do continente americano (Webster 1967). Entre os poucos representantes do gênero utilizados pelo homem destacam as espécies conhecidas no Brasil como quebrapedra, arrebenta-pedra ou erva-pombinha, entre elas P. niruri L., P. amarus Schum. \& Thonn e P. tenellus Roxb. Müll. Arg., reconhecidas popularmente por suas propriedades diuréticas, sendo utilizadas na eliminação de cálculos renais, mais recentemente foi descoberta atividade antiviral, com possíveis aplicações no tratamento da Hepatite-B e câncer em várias espécies do gênero (Lorenzi \& Matos 2002). Poucas são as espécies utilizadas como ornamentais, (e.g. P. epiphyllanthus L.). Algumas brasileiras, entretanto, apesar de não cultivadas, possuem grande potencial paisagístico, entre elas: $P$. acuminatus Müll. Arg., P. gladiatus Müll. Arg., P. scoparius Müll. Arg., P. flagelliformis Müll. Arg., P. klotzschianus Müll. Arg., P. spartioides Müll. Arg. e P. angustissimus
Müll. Arg., que embelezam os campos rupestres e restingas com seus ramos modificados em cladódios.

Webster $(1956 ; 1957 ; 1958)$ descreveu um tipo especializado de ramificação dentro do gênero, que denominou filantóide; em plantas deste tipo, as folhas aparecem no eixo principal, apenas em poucos nós acima dos cotilédones, estando a maioria delas em ramos laterais, plagiotrópicos e caducos, que também produzem as flores como ocorre em P. niruri, P. amarus Schum. Thonn., P. claussenii Müll. Arg., P. orbiculatus L. C. Rich. e P. heteradenius Müll. Arg.

Nas flores estaminadas de Phyllanthus, o disco é obrigatoriamente dividido em segmentos isômeros e alternos aos lobos do cálice, podendo ser pateliformes, cuneados, ou mais raramente falcados. Nas flores pistiladas, o disco é geralmente inteiro, sendo em poucas espécies dividido em segmentos semelhantes ao das flores estaminadas, como em P. heteradenius.

Harley \& Mayo (1980) referiram para a Bahia cinco espécies de Phyllanthus, das quais três foram encontradas na Chapada Diamantina: P. flagelliformis, $P$. klotzschianus e P. orbiculatus.

O presente trabalho é o resultado do levantamento das espécies de Phyllanthus na região da Chapada Diamantina realizado como parte do projeto Flora da Bahia.

\section{Material e métodos}

Foram estudadas coleções de Phyllanthus da Chapada Diamantina dos herbários ALCB, CEPEC, HUEFS, MBM, R, RB, SP, SPF e observadas populações de oito espécies de Phyllanthus (P. klotzschianus, P. orbiculatus, $P$. scoparius, $P$. spartioides, $P$. angustissimus, P. amarus, P. flagelliformis e P. niruri).

Os termos utilizados nas descrições das espécies estão de acordo com Radford (1974) e Font Quer (1965). As ilustrações foram realizadas com base em material herborizado reidratado ou fixado em álcool $70 \%$. 
Além das fontes bibliográficas, as observações sobre as espécies incluem informações das etiquetas das exsicatas.

\section{Resultados e discussão}

\section{Phyllanthus L.}

Ervas, arbustos ou árvores monóicos ou, mais raramente, dióicos. Folhas simples, inteiras, alternas, estipuladas, às vezes presentes apenas nas plantas jovens, então os ramos modificados em cladódios; pecíolos menores que as lâminas. Inflorescências cimosas, axilares, paucifloras, às vezes reduzidas a uma única flor; flores estaminadas monoclamídeas, sépalas 4-6; disco nectarífero usualmente segmentado; estames (2-)3-5(-15); filetes livres ou unidos; anteras livres ou unidas, rimosas, rimas horizontais a verticais; grãos de pólen prolatos a esféricos, colporados a porados; flores pistiladas monoclamídeas, sépalas 4-6; disco nectarífero inteiro, freqüentemente pateliforme a cupuliforme, raramente segmentado; ovário 3-locular; óvulos 2 por lóculo; estiletes 3 , livres ou unidos na base, geralmente divididos. Fruto cápsula septicida, separando-se na maturidade em mericarpos, raramente baga ou drupa; sementes geralmente 2 por lóculo, angulosas, triangulares em seção transversal.

Chave para as espécies de Phyllanthus da Chapada Diamantina, Bahia

1. Ramos cilíndricos a levemente achatados, não modificados em cladódios; folhas desenvolvidas presentes em todas as fases da vida da planta

2. Flores pistiladas e estaminadas dispostas na mesma inflorescência

3. Flores estaminadas com filetes unidos, tecas convergentes 1. P. amarus

3. Flores estaminadas com filetes livres, tecas divergentes

4. Flores alvas, disco da flor pistilada anular, pedicelo $7-10 \mathrm{~mm}$ compr.

3. P. claussenii

4. Flores rubras, disco da flor pistilada com 6 glândulas, pedicelo 3-4mm compr. 8. P. orbiculatus

2. Flores pistiladas e estaminadas dispostas em inflorescências separadas

5. Flores pistiladas com disco anular, ramos dos estiletes capitados 7. P. niruri

5. Flores pistiladas com disco segmentado, ramos dos estiletes agudos

6. Folhas membranáceas, disco da flor estaminada com 5 glândulas falcadas 5. P. heteradenius

6. Folhas subcoriáceas, disco da flor estaminada com 6 glândulas arredondadas 11. Phyllanthus sp.

1. Ramos modificados em cladódios, folhas desenvolvidas presentes apenas nas plantas jovens, reduzidas a escamas nas plantas mais velhas

7. Cladódios cilíndricos a subcilíndricos em seção transversal, geralmente com até $0,4 \mathrm{~cm}$ larg.

8. Sépalas 5 , valvas das tecas assimétricas 10. P. spartioides

8. Sépalas 6 , valvas das tecas simétricas

9. Ramos dos estiletes obtusos. 2. P. angustissimus

9. Ramos dos estiletes capitados 9. P. scoparius

7. Cladódios conspicuamente achatados em seção transversal, com 0,5 a $1,5 \mathrm{~cm}$ larg.

10. Flores sésseis, sépalas 5, filetes unidos, rimas oblíquas 6. P. klotzschianus

10. Flores pediceladas, sépalas 6 , filetes livres, rimas horizontais 4. P. flagelliformis 
1. Phyllanthus amarus Schumach. \& Thonn., Kongel. Beskr. Guin. Pl. p. 421. 1827

Fig. 1-6

Erva, $30-40 \mathrm{~cm}$ alt., glabra, com ramificação filantóide, ramos cilíndricos a levemente achatados, não modificados em cladódios. Estípulas oval-lanceoladas a lanceoladas, acuminadas, ca. $2 \mathrm{~mm}$ compr. Folhas subsésseis, membranáceas, oblongas, 8-10×3-4mm, ápice arredondado, base obtusa, margem inteira, pecíolo ca. $1 \mathrm{~mm}$ compr. Flores em címulas bissexuais, com uma flor pistilada e uma flor estaminada; brácteas lanceoladas, acuminadas; flores estaminadas ca. $2 \mathrm{~mm}$ compr., pedicelo ca. $1 \mathrm{~mm}$ compr., sépalas 5 , obovadas a elípticas, acuminadas, obtusas, inteiras, translúcidas nas margens, esverdeadas; disco com 5 glândulas pateliformes; estames 2, raramente 3, filetes totalmente unidos, tecas convergentes, rimas horizontais a oblíquas; flores pistiladas ca. $2 \mathrm{~mm}$ compr., pedicelo ca. $1,5 \mathrm{~mm}$ compr., chegando a $2 \mathrm{~mm}$ no fruto; sépalas 5, oboval-oblongas, apiculadas a agudas, côncavas, inteiras, translúcidas nas margens, esverdeadas; disco anular com 5 apículos; ovário globoso, verde; estiletes levemente 2-partidos, patentes. Fruto cápsula, ca. $3 \mathrm{~mm}$ compr. Sementes ca. $1 \mathrm{~mm}$ compr., castanho-claras, estriadas.

Material examinado: BRASIL. Bahia: Lençóis, 8/III/1984, fl., Noblick 3083 (HUEFS). Rio de Contas, 13/IX/1998, fr., Silva et al. 148 (HUEFS).

$P$. amarus é uma espécie pouco freqüente na área de estudo, tendo sido coletada apenas em duas localidades. Aparentemente nativa das Américas, mas atualmente pantropical, é a mais ruderal e amplamente distribuída espécie do gênero (Webster 2002).

$P$. amarus não é facilmente distinguível, vegetativamente, das outras espécies da Chapada com ramificação filantóide. Porém, as inflorescências bissexuais com duas flores e os estames completamente unidos, identificam a espécie.
2. Phyllanthus angustissimus Müll. Arg., Linnaea 32:55.1863.

Fig. 7-12

Subarbusto, até 1,5m alt., glabro, ramos modificados em cladódios linear-lanceolados a cilíndricos, estriados em ambas as faces, 2-20 $\times$ 0,15-0,4cm. Estípulas oval-lanceoladas, ca. $1 \mathrm{~mm}$ compr., agudas. Folhas reduzidas, escamiformes, escariosas, linear-lanceoladas, 5-7 × 1-2mm, ápice acuminado a apiculado, base atenuada, pecíolo ca. $1 \mathrm{~mm}$ compr. Flores em címulas unissexuais, dispostas nas margens dos cladódios, brácteas triangulares, escariosas, ca. $1 \mathrm{~mm}$ compr., caducas, vermelhas; flores estaminadas ca. 3-4mm compr., pedicelo ca. $1 \mathrm{~mm}$ compr., sépalas 6 , obtusas, amarelo-esverdeadas, disco com 6 glândulas pateliformes; estames 3, filetes totalmente unidos, tecas convergentes, com valvas simétricas, rimas suboblíquas a verticais; flores pistiladas 5-6mm compr., pedicelo ca. 1-2mm compr., sépalas 6 , obtusas, creme, disco anular; ovário globoso, verde; estiletes eretos, 2-partidos, ramos obtusos. Fruto cápsula, ca. 4mm compr. Sementes ca. 2,3mm compr., purpúreas a negras, verruculosas.

Material examinado: BRASIL. Bahia: Andaraí, 9/X/1987, fr., Guedes et al. 1407 (SPF); Lençóis, 19/XII/1984, fl., Stannard et al. 7201 (SPF); 16/II/1994, fr., Harley et al. 14146 (SPF); 1/XI/1973, fl., Joly s/n (SP120906); 22/XI/1994, fr., Melo et al. 1243 (HUEFS); 31/VIII/1994, fl., Stradmann et al. 662 (CEPEC); fr., Bautista et al. 3479 (ALCB); 27/V/1980, fl. Harley 22699 (MBM, ALCB); 24/V/1980, fl., Harley 22525 (SPF, CEPEC); 21/V/1980, fl., Harley 22291 (CEPEC, SPF); 27/XI/1986, fr., Loizeau 539 (CEPEC); 28/VI/95, fr., Guedes et al. 1944 (HUEFS, $\mathrm{SPF}) ; 30 / \mathrm{VI} / 1995$, fl., Stradmann et al. 537 (HUEFS); fr., Guedes 390 (HUEFS); 29/VI/1983, fl., Queiroz 635 (HUEFS); 16/XI/1983, fr., Bautista et al. 1288 (RB, MBM); 18/XII/1981, fr., Carvalho 972 (HUEFS); 14/IX/1956, fr., Pereira 2227 (SPF); 
Palmeiras, 11/I/1987, fl., Queiroz et al. 1925, 1907 (HUEFS, MBM).

$P$. angustissimus foi coletada com flores e frutos praticamente durante todos os meses do ano. Vegetativamente é muito semelhante a P. scoparius Müell. Arg., da qual se diferencia por suas anteras de rimas suboblíquas e ramos dos estiletes obtusos, enquanto em $P$. scoparius as rimas são verticais, os ramos dos estiletes agudos.

Segundo Cordeiro (1992), esta espécie também ocorre nos campos rupestres de Minas Gerais e em restingas na Bahia, caracterizando uma distribuição geográfica do tipo disjunta.

3. Phyllanthus claussenii Müll. Arg., Linnaea 32:40.1863.

Fig. 13-17

Erva até 1,2m alt., glabra, ramificação não filantóide, ramos cilíndricos a levemente achatados, não modificados em cladódios. Estípulas lanceoladas, margem denteada, ca. $2 \mathrm{~mm}$ compr. Folhas membranáceas, subsésseis, largamente elípticas a largamente obovais, 5-14 $\times 5-9 \mathrm{~mm}$, ápice apiculado a mucronulado, base arredondada a acuminada, margem inteira, face adaxial verde-vinácea, face abaxial esverdeada, pecíolo ca. $1 \mathrm{~mm}$ compr. Flores em címulas bissexuais, flor pistilada 1 , flores estaminadas 1-2; brácteas estreitamente triangulares, ca. $1 \mathrm{~mm}$ compr.; flores estaminadas 2-3mm compr., pedicelo ca. $2 \mathrm{~mm}$ compr., sépalas (5-)6, elípticas a ovais, agudas, denteadas nas margens, creme a esverdeadas; disco com (5-)6 glândulas papilosas; estames 3, livres; tecas divergentes, rimas horizontais; flores pistiladas $2-3 \mathrm{~mm}$ compr., pedicelo 6-10mm compr.; sépalas (5-)6, elípticas a obovais, ápice arredondado a agudo, côncavas, levemente denteadas nas margens, creme a esverdeadas, disco anular, papiloso; ovário globoso, amarelo-esverdeado; estiletes profundamente 2-partidos, ramos capitados. Fruto cápsula, ca. $3 \mathrm{~mm}$ compr. Sementes ca. 1,3mm compr., castanhas, verruculosas.

Material examinado: BRASIL. Bahia:
Abaíra, 11/IV/1994, fl., Ganev 3081 (HUEFS); 7/XII/1992, fr., Hind et al. s/n (HUEFS 50461); 26/XII/1992, fr., Ganev 1751 (HUEFS, SPF, CEPEC). Caetité, 8/II/1997, fr., Guedes et al. 5216 (HUEFS).

P. clausseni é pouco freqüente na Chapada Diamantina, só coletada nos Municípios de Abaíra e Caetité, com flores e frutos nos meses de dezembro a fevereiro.

P. clausseni possui flores estaminadas e pistiladas muito semelhantes às de P. flagelliformis. Entretanto, a presença de ramos cilíndricos a levemente achatados nunca modificados em cladódios diferencia-o facilmente desta espécie, que apresenta ramos modificados em cladódios e folhas reduzidas escamiformes.

Segundo Webster (2002) a espécie ocorre no Nordeste, Minas Gerais, São Paulo e Paraná.

4. Phyllanthus flagelliformis Müll. Arg., Linnaea 32:54.1863.

Fig. 18-24

Subarbusto até 1,2m alt., glabro, ramos modificados em cladódios, lanceolados a obovados, achatados, coriáceos, estriados em ambas as faces, 2,5-15,0 × 0,6-1,5cm. Folhas desenvolvidas, membranáceas, limbo oboval a largamente oboval, 4-10 × 3-9mm, ápice mucronado, base arredondada, margem inteira, pecíolo ca. $2 \mathrm{~mm}$ compr. Flores em címulas bissexuais, dispostas nas margens dos cladódios; flor pistilada 1, flores estaminadas 2-6, brácteas triangulares, ca. $1 \mathrm{~mm}$ compr., vermelhas, denteadas nas margens; flores estaminadas ca. $5 \mathrm{~mm}$ compr., pedicelo $2-4 \mathrm{~mm}$ compr., vináceo, sépalas 6 , arredondadas, denteadas nas margens, verde-amareladas, disco com 6 glândulas pateliformes, subturbinadas, papilosas; estames 3, livres, tecas divergentes, rimas horizontais; flores pistiladas ca. 2-3mm compr., pedicelo 2-4 (-5-8)mm compr. no fruto, vináceo, sépalas 6 , obtusas, denteadas nas margens, amarelo-esverdeadas, disco anular, papiloso, ovário globoso, 


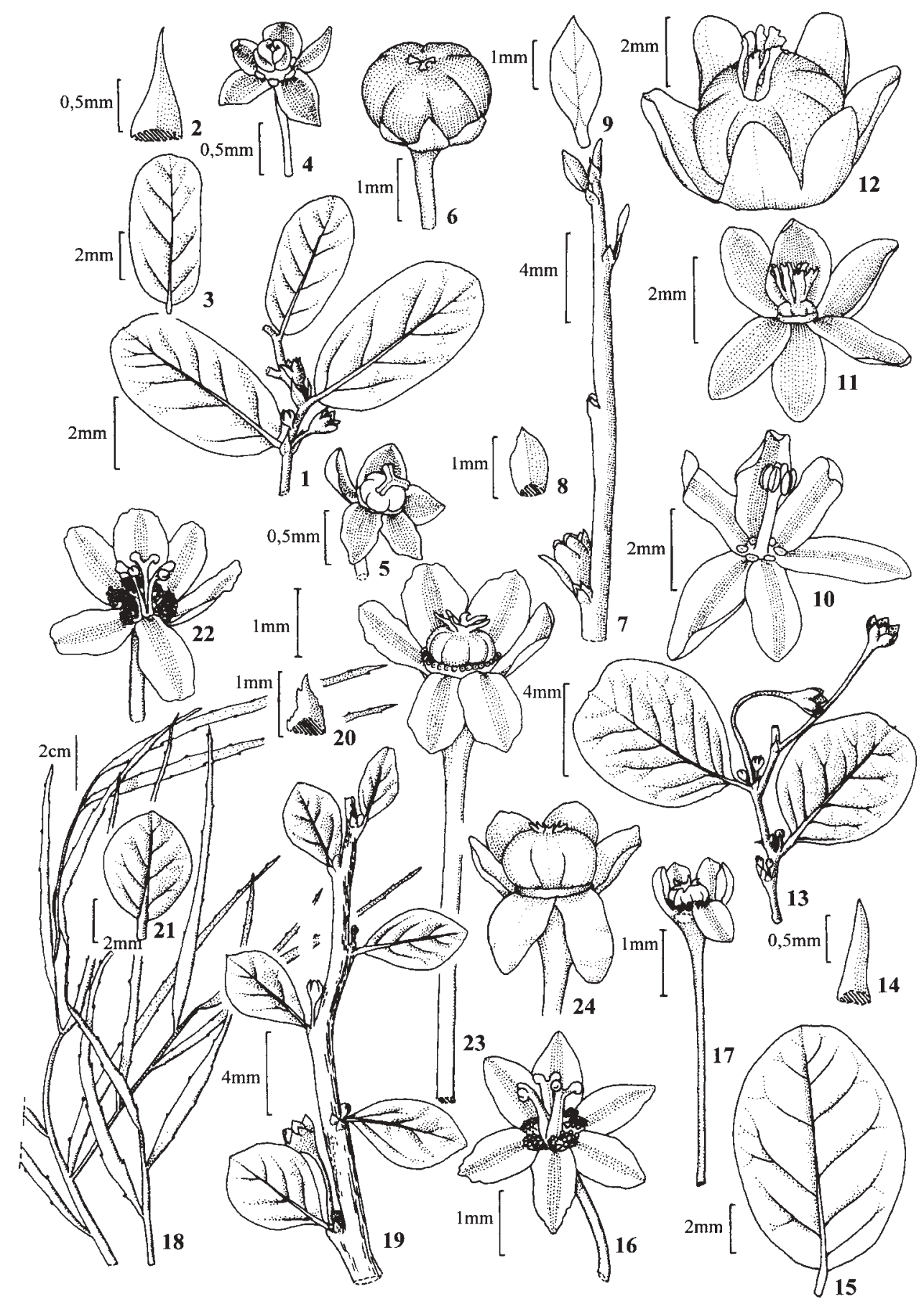

Figuras 1-6. Phyllanthus amarus Schumach. \& Thonn. (Noblick 3083). 1. ramo florífero; 2. estípula; 3. folha face abaxial; 4. flor estaminada; 5. flor pistilada; 6. fruto. Figuras 7-12. Phyllanthus angustissimus Müll. Arg. (Queiroz 1907). 7. ramo florífero; 8. estípula; 9 . folha face adaxial; 10 . flor estaminada; 11 . flor pistilada; 12 . fruto. Figuras 13-17. Phyllanthus claussenii Müll. Arg. (Ganev 1751). 13. ramo florífero; 14. estípula; 15. folha face adaxial; 16. flor estaminada; 17. flor pistilada. Figuras 18-24. Phyllanthus flagelliformis Müll. Arg. (Harley 2832). 18. hábito; 19. ramo florífero; 20. estípula; 21. folha face abaxial; 22. flor estaminada; 23. flor pistilada; 24 . fruto. 
verde; estiletes eretos, profundamente 2-partidos, ramos divaricados. Fruto cápsula, ca. 3mm compr. Sementes ca. $2 \mathrm{~mm}$ compr., castanhas, verruculosas.

Material examinado: BRASIL. Bahia: Abaíra, 10/IX/1992, fr., Ganev 1058 (HUEFS, SP); 24/XII/1991, fl., Harley 50325 (HUEFS, SP); 25/XII/1988, fl., Harley et al. 27739 (CEPEC, SPF). Brumado, 23/III/1977, fl., Harley 198 (HUEFS). Iguaçu, 1/III/1992, fl., Ferreira 489 (ALCB). Jacobina, 6/IV/1996, fl., Guedes 2868 (HUEFS); 30/VII/1994, fl., Souza 04 (HUEFS); 19/XI/1986, fl., Webster et al. 25727 (MBM, SPF). Jussiape, 17/II/1987, fl., Harley et al. 24353 (SPF, SP, MBM). Lençóis, 27/IV/1995, fl., Pereira 1875 (HUEFS); 13/VI/1981, fl., Mori \& Boom 14406 (CEPEC); 12/III/1997, fl., Gasson 6187 (HUEFS, SP); 28/XI/1994, fr., Guedes 1448 (HUEFS); 26/IX/1994, fr., Giulietti et al. 834 (ALCB). Morro do Chapéu, 17²VI/1981, fl., Mori \& Boom 14530 (CEPEC); Palmeiras, 8/XI/97, fl., Guedes et al. 5476 (ALCB). Pindobaçu, 25/X/1993, fr., Ganev 2347 (HUEFS). Rio de Contas, 21/I/1974, fl., Harley 15393 (CEPEC); 28/III/1977, fl., Harley 20115 (CEPEC); 13/XII/1984, fl., Giulietti et al. 6769 (SPF, MBM); 13/XI/1998, fr., Silva et al. 161 (HUEFS). Saúde, 4/IV/1996, fl., Harley 2832 (HUEFS).

P. flagelliformis é espécie freqüente nos municípios de Jacobina, Palmeiras, Lençóis e Rio de Contas. É encontrada florida e com frutos praticamente ao longo de todo o ano. Até o presente há apenas um registro desta espécie fora da Chapada, no município de Pindobaçu, na Bahia.

Esta espécie é vegetativamente semelhante a $P$. klotzschianus e $P$. angustissimus, sendo possível diferenciá-las pelos estames livres em $P$. flagelliformis e unidos nestas duas espécies, assim como pelas flores sésseis em P. klotzschianus e subsésseis em $P$. angustissimus, contrapostas às conspícuamente pediceladas de P. flagelliformis.
5. Phyllanthus heteradenius Müll. Arg. in Mart., Fl. bras. 11(2):63.1873.

Fig. 25-32

Erva até $15 \mathrm{~cm}$ alt., glabra, ramificação não filantóide, ramos cilíndricos a levemente achatados não modificados em cladódios. Estípulas largamente triangulares a obovais, margem denteada, ca. $1 \mathrm{~mm}$ compr. Folhas membranáceas, subsésseis, largamente orbiculares a largamente elípticas, 7-10 ×5-6mm, ápice obtuso a agudo, base arredondada, margem inteira, face adaxial verde-escura, face abaxial verde-clara; pecíolo ca. $1 \mathrm{~mm}$ compr. Flores em címulas unissexuais, 2-3 flores; brácteas oval-lanceoladas; flores estaminadas ca. $3 \mathrm{~mm}$ compr., pedicelo ca. 1,3mm compr., sépalas 5, largamente ovais a obovais, ápice agudo, translúcidas nas margens, cremes; disco com 5 glândulas falcadas; estames 3 , filetes unidos até $1 / 3$ do comprimento; tecas divergentes, rimas horizontais; flores pistiladas ca. 3,5mm compr., pedicelo ca. $1 \mathrm{~mm}$ compr., sépalas 5, largamente ovais, ápice agudo, translúcidas nas margens, disco com 5 glândulas falcadas; ovário globoso; estiletes 2-partidos, ramos eretos, capitados. Fruto cápsula, 2-3mm compr. Sementes castanhas, verruculosas.

Material examinado: BRASIL. Bahia: Rio de Contas, 21/I/1974, fl. fr., Harley 15387 (CEPEC).

$P$. heteradenius foi coletada na Chapada apenas uma única vez, em campo rupestre, sendo que sua ocorrência é referida por Webster (2002) para o Nordeste do Brasil. Separa-se das outras espécies do gênero, na região, principalmente pelo disco da flor estaminada com glândulas falcadas.

6. Phyllanthus klotzschianus Müll. Arg., Linnaea 32:53.1863.

Fig. 33-37

Subarbusto monóico, até 1,5m alt., glabro, ramos modificados em cladódios lanceolados, obovais a falcados, achatados, estriados em ambas as faces, coriáceos, 2-10 × 0,5-1,0cm, 
ápice arredondado a acuminado, base atenuada. Folhas desenvolvidas caducas, presentes apenas nos ramos jovens da planta, obovais a lanceoladas, 5-10 × 2-6mm, ápice agudo a obtuso, margem inteira, base obtusa; pecíolo $1 \mathrm{~mm}$ compr.; folhas reduzidas escamiformes, escariosas, lanceoladas, agudas, 2-5mm compr. Flores sésseis, dispostas nas margens dos cladódios, solitárias ou em címulas unissexuais de 2-3 flores; brácteas triangulares, ca. $1 \mathrm{~mm}$ compr.; flores estaminadas ca. 2-3mm compr.; sépalas 5, largamente obovais, subcoriáceas, verde-amareladas; disco com 5 glândulas pateliformes; estames 3 , filetes totalmente unidos, valvas de cada teca assimétricas, rimas oblíquas; flores pistiladas ca. 3mm compr., sépalas 5, obtusas, subcoriáceas, verdeamareladas; disco anular, ovário globoso, verde; estiletes eretos, profundamente 2-partidos. Fruto cápsula, ca. 3-4 × 3-5mm. Sementes ca. 3mm compr., pretas a castanho-escuras, verruculosas.

Material examinado: BRASIL. Bahia: Abaíra, 16/IV/1994, fl., França et al. 965 (HUEFS); 8/VI/1992, fl., Ganev 443 (HUEFS); 30/V/1994, fl., Ganev 3262 (HUEFS); 31/X/1996, fl., Queiroz \& Silva PCD3860 (HUEFS); 10/VII/1995, fr., Queiroz et al. 4404 (HUEFS); 26/XII/1988, fl., Harley 27776 (CEPEC, SPF); 29/I/1992, fl., Stannard et al. 51103 (HUEFS, CEPEC, SP, SPF); 10/I/1992, fl., Harley et al. 51260 (SPF, SP); 10/I/1994, fl., Harley et al. 51281 (HUEFS, CEPEC, SP, SPF); 2/II/1992, fl., Pirani et al. 51458 (SPF). Andaraí, 9/VIII/1987, fr., Queiroz 1799 (HUEFS); 14/II/1977, fr., Harley 18662 (CEPEC, SPF). Barra da Estiva, 17/XI/1988, fl., Harley 26905 (CEPEC, MBM, SPF); 28/I/1974, fl., Harley 15535 (RB); 19/VII/1981, fl., Giulietti et al. CFCR1349 (SPF). Jacobina, 18/XI/1986, fl., Queiroz et al. 1182 (HUEFS); 27/II/1974, fl. fr., Harley 16528 (CEPEC). Lençóis, 23/XI/1994, fl., Melo et al. 1271 (HUEFS). Morro do Chapéu, 12/VII/1979, fl., Ribeiro 59 (CEPEC); 19/XI/1986, fl., Queiroz et al. 1273 (HUEFS); Rio do Ferro Doido,
17/I/1977, fl., Hatschbach 39708 (MBM); 1/III/1977, fr., Harley 19199 (CEPEC, SPF); 6/IX/1980, fl., Furlan et al. CFCR272 (SPF). Mucugê, 10/X/1987, fl., Queiroz et al. 1858 (HUEFS); 2/I/1984, fl., Hatschbach 47532 (CEPEC, MBM); 12/X/1998, fl., Silva et al. 113 (HUEFS); 12/III/1980, fl., Harley et al. 2078 (CEPEC); 26/VII/1979, fr., Mori et al. 12574 (RB); 16/XII/1984, fl., Giulietti et al. 7013 (SPF); 12/XI/1998, fl., Oliveira et al. 30 (HUEFS); 20/VII/1981, fr., Giulietti et al. 1423 (SPF). Piatã, 12/XI/1996, fl., Bautista \& Hind 4218 (HUEFS). Rio de Contas, 2/IX/1993, fl., Ganev 2193 (HUEFS); 16/V/1983, fl., Hatschbach 46444 (CEPEC, MBM); 8/XI/1988, fl., Harley 26035 (CEPEC, SPF); 27/III/1977, fr., Harley 20054 (CEPEC, SPF); 4/III/1994, fr., Sano et al. CFCR14871 (SPF); 27/III//1998, fr., Carneiro et al. 10 (HUEFS). Utinga, 26/IX/85, fl., Wanderley et al. s/n (SP 210116).

P. klotzschianus é espécie muito frequiente na Chapada Diamantina, coletada com flores e frutos durante praticamente o ano todo, principalmente nos campos rupestres de Mucugê, Abaíra, Morro do Chapéu e Rio de Contas. Além da Chapada Diamantina; também é encontrada em campos rupestres de Minas Gerais e em restingas da Bahia, Espírito Santo e Sergipe.

$\mathrm{Na}$ área de estudo é encontrada entre rochas, sendo facilmente distinguível das demais espécies com cladódios da Chapada, por suas flores sésseis.

7. Phyllanthus niruri L., Sp. pl. 2:981.1753. Fig. 38-45

Erva ca. $30 \mathrm{~cm}$ alt., glabra, com ramificação filantóide, ramos cilíndricos a levemente achatados não modificados em cladódios. Estípulas linear-lanceoladas, 2-3mm compr., longamente acuminadas. Folhas membranáceas, subsésseis, oblongas a elípticas, 8-13 ×3-4mm, ápice arredondado, base cordada, assimétrica, margem inteira; pecíolo 0,5-1,0mm compr. Flores em címulas unissexuais, as estaminadas 
proximais com 3-7 flores, as pistiladas distais com uma única flor; brácteas linear-lanceoladas, ca. 1-1,8mm compr.; flores estaminadas ca. $2 \mathrm{~mm}$ compr., pedicelo ca. $1 \mathrm{~mm}$ compr., sépalas 5 , largamente obovais, côncavas, inteiras, verde-claras; disco com 5 glândulas cuneadas, papilosas; estames 3, filetes livres a totalmente unidos; tecas convergentes, rimas horizontais a oblíquas; flores pistiladas ca. $2,5 \mathrm{~mm}$ compr., pedicelo 3-4mm compr., sépalas 5, largamente obovais a elípticas, inteiras, verde-claras; disco anular; ovário globoso, verde; estiletes livres, 2-partidos, eretos, capitados. Fruto cápsula, ca. $2 \mathrm{~mm}$ compr. Sementes $1,5 \mathrm{~mm}$ compr., castanho-escuras, verruculosas.

Material examinado: BRASIL. Bahia: Andaraí, 23/XI/1985, fl., Hatschbach \& Zelma 50126 (CEPEC, MBM). Campo Formoso, 29/IV/1981, fr., Orlandi 375 (RB). Lençóis, 29/XI/1998, fr., Carneiro et al. 86 (HUEFS); 28/XI/1998, fr., Oliveira et al. 155 (HUEFS). Morro do Chapéu, 2/VI/1980, fr., Harley 23009 (CEPEC); 11/XI/1998, fr., Carneiro et al. 52 (HUEFS). Rio de Contas, 22/XII/1988, fl., Harley \& Hind 27336 (CEPEC).

$P$. niruri é espécie ruderal, encontrada florida e com frutos durante todo o ano. É pouco freqüente na Chapada Diamantina. Segundo Webster (1970), distribui-se desde o México até Argentina e Brasil.

P. niruri e P. amarus ocorrem simpatricamente na região de Rio de Contas, mas apesar de sua semelhança, diferenciam-se pelas folhas assimétricas, inflorescências unissexuais e estiletes capitados em P. niruri e folhas simétricas, inflorescências bissexuais e estiletes agudos em $P$. amarus.

8. Phyllanthus orbiculatus Rich., Act. Soc. Hist. Nat. Paris 1:113.1792.

Fig. 46-51

Erva a subarbusto até $50 \mathrm{~cm}$ alt., com ramificação filantóide, glabros, ramos cilíndricos a levemente achatados, não modificados em cladódios. Estípulas ca. $1 \mathrm{~mm}$ compr., trian- gulares, agudas a acuminadas, inteiras. Folhas membranáceas, subsésseis, arredondadas, largamente ovais a orbiculares, $4-10 \times 3-8 \mathrm{~mm}$, ápice agudo a acuminado, base obtusa a arredondada, margem inteira, face adaxial verdeescura a rubra, face abaxial verde-clara a avermelhada; pecíolo $1 \mathrm{~mm}$ compr. Flores em címulas bissexuais, com 2-3 flores estaminadas e uma flor pistilada; brácteas lanceoladas, ca. $0,6 \mathrm{~mm}$ compr., margem denteada; flores estaminadas ca. $2,5 \mathrm{~mm}$ compr., pedicelo 2,5-3,0mm compr., sépalas 6, ovais a elípticooblongas, agudas, inteiras, translúcidas nas margens, vermelhas a purpúreas; disco com 6 glândulas pateliformes; estames 3, livres, tecas divergentes, rimas horizontais; flores pistiladas ca. $4 \mathrm{~mm}$ compr., pedicelo ca. $3-4 \mathrm{~mm}$ compr., sépalas 6, elípticas a linear-oblongas, agudas, inteiras, translúcidas nas margens, vermelhas a purpúreas; disco com 3 glândulas; ovário globoso, verde; estiletes 2-partidos, livres, exceto na base, ramos agudos. Fruto cápsula, ca. $2 \mathrm{~mm}$ compr. Sementes $2 \mathrm{~mm}$ compr, castanhas, verruculosas.

Material examinado: BRASIL. Bahia: Catolés, 23/X/1999, fr., Miranda-Silva et al. 304 (HUEFS). Mucugê, 20/VII/81, fl., Giulietti et al. CFCR 1488 (SPF). Rio de Contas, 21/I/1974, fr., Harley 15386 (HUEFS); 13/XI/1998, fr., Silva et al. 162 (HUEFS).

P. orbiculatus é pouco comum na Chapada Diamantina, porém possui ampla distribuição nos cerrados e campos rupestres de todo o Brasil. Webster (1957) refere-o para toda a América do Sul. Observada com flores e frutos, nos meses de novembro a fevereiro.

Entre as espécies com ramificação filantóides, diferencia-se por suas folhas arredondadas a orbiculares, com nervura de coloração vermelha a púrpura.

9. Phyllanthus scoparius Müll. Arg., Mart., Fl. bras. 11(2):74.1873.

Fig. 52-57

Subarbusto ca. $1 \mathrm{~m}$ alt., glabro, ramos modificados em cladódios, eretos, subfiliformes, 


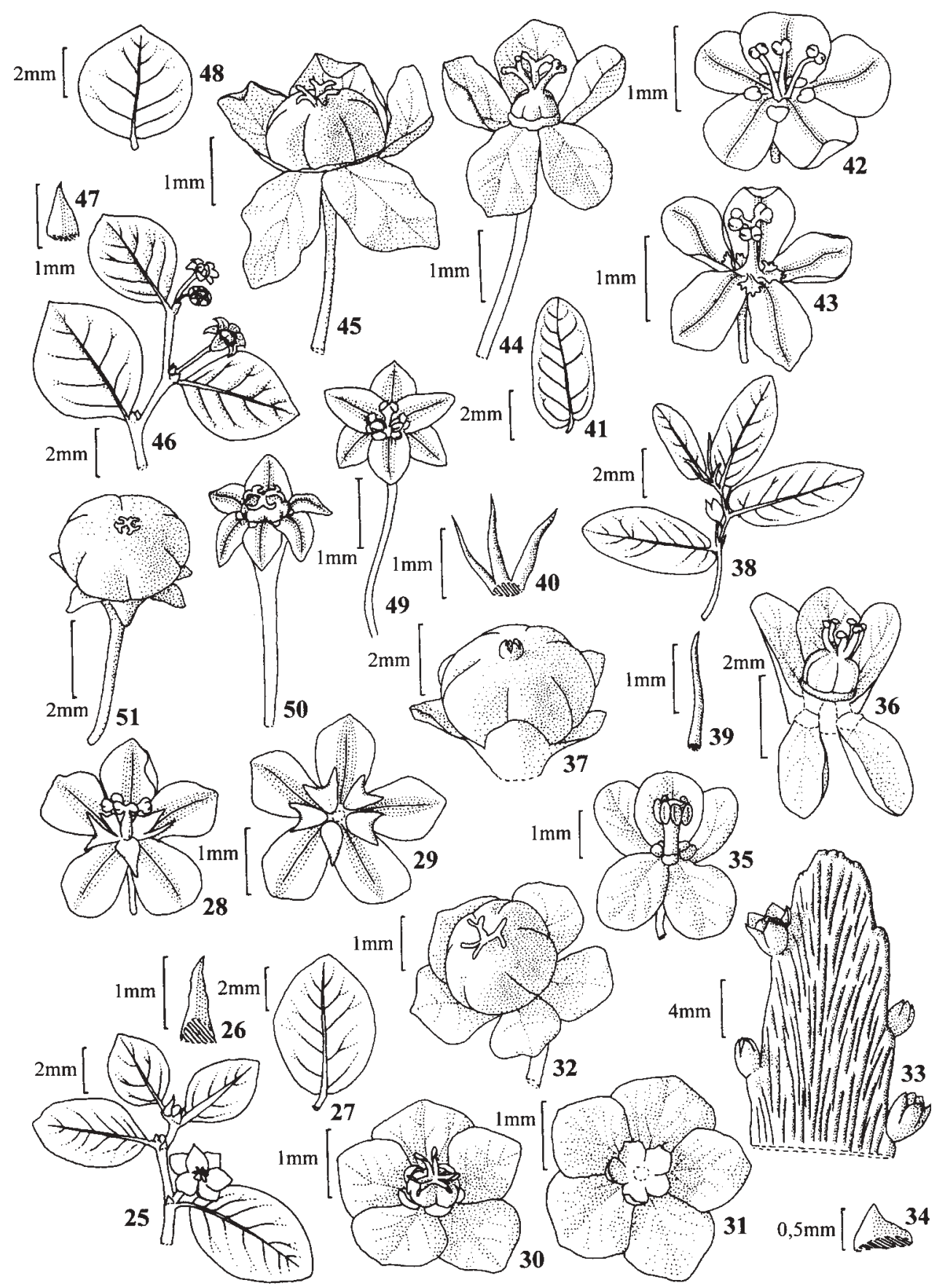

Figuras 25-32. Phyllanthus heteradenius Müll. Arg. (Harley 15387). 25. ramo florífero; 26. estípula; 27. folha face abaxial; 28. flor estaminada; 29. detalhe do disco nectarífero da flor estaminada; 30. flor pistilada; 31 . detalhe do disco nectarífero da flor pistilada; 32. fruto. Figuras 33-37. Phyllanthus klotzschianus Müll. Arg. (Giulietti 3366). 33. ramo florífero; 34. estípula; 35. flor estaminada; 36. flor pistilada; 37. fruto. Figuras 38-45. Phyllanthus niruri L. (Orlandi 375; Stannard 4645). 38. ramo florífero; 39-40. variação morfológica da estípula; 41. folha face abaxial; 42-43. variação morfológica da flor estaminada; 44. flor pistilada; 45. fruto. Figuras 46-51. Phyllanthus orbiculatus Rich. (Harley 15386). 46. ramo florífero; 47. estípula; 48. folha face abaxial; 49. flor estaminada; 50. flor pistilada; 51. fruto. 
cilíndricos, 1-2mm larg. Estípulas ca. $2 \mathrm{~mm}$ compr., oval-lanceoladas, ápice agudo, margem levemente denteada. Folhas desenvolvidas, sésseis a subsésseis, caducas, escamiformes, escariosas, ápice agudo, base atenuada, margem inteira; pecíolo ca. $1 \mathrm{~mm}$ compr. Flores em címulas unissexuais, as estaminadas proximais, com 2-3 flores, as pistiladas distais, com uma única flor; brácteas ca. 1,5mm compr., oval-lanceoladas, agudas, avermelhadas; flores estaminadas ca. $4,5 \mathrm{~mm}$ compr., pedicelo ca. $1,5 \mathrm{~mm}$ compr., sépalas 6 , as três mais externas elípticas, mucronadas a acuminadas, as três mais internas obovais, obtusas, agudas; disco com 6 glândulas pateliformes; estames 3, filetes unidos; tecas convergentes com valvas simétricas; rimas verticais; flores pistiladas ca. $5 \mathrm{~mm}$ compr., pedicelo ca. $2,6 \mathrm{~mm}$ compr., sépalas 6 , as três mais externas elípticas, obtusas, mucronadas a acuminadas, as três mais internas obovais, obtusas, ápice agudo; disco anular; ovário globoso, verde; estiletes eretos, 2-partidos, ramos capitados. Fruto cápsula, ca. $4 \mathrm{~mm}$ compr. Sementes ca. 2,3mm compr., castanho-escuras, verruculosas.

Material examinado: BRASIL. Bahia: Mucugê, 26/III/1980, fr., Harley 20991 (SPF, HUEFS). Palmeiras, 20/XII/1984, fl., MelloSilva et al. CFCR 7300 (SPF); 19/XII/1984, fl., Stannard et al. CFCR 7137 (SPF).

$P$. scoparius é uma espécie pouco freqüente na Chapada Diamantina, sendo endêmica de Minas Gerais e Bahia, na Cadeia do Espinhaço. Diferencia-se P. angustissimus por apresentar rimas verticais e ramos dos estiletes capitados, enquanto $P$. angustissimus apresenta rimas suboblíquas a verticais e ramos dos estiletes obtusos.

10. Phyllanthus spartioides $\mathrm{Pax} \& \mathrm{~K}$. Hoffm. in Repert. Spec. Nov. Regni. Veg. 19:174.1923.

Fig. 58-62

Arbusto a subarbusto até $1,3 \mathrm{~m}$ alt., glabro, ramos modificados em cladódios, 0,5-1 mm larg., cilíndricos. Estipulas triangulares, ca. $1 \mathrm{~mm}$ compr., agudas, base assimétrica. Folhas desenvolvidas sésseis a subsésseis, membranáceas, caducas, presentes apenas nas partes jovens dos ramos; folhas reduzidas, escamiformes, linear-lanceoladas, sésseis, escariosas, 4-6 0 0,5-1,0mm, acuminadas, base atenuada, margem inteira. Flores em címulas unissexuais; brácteas lanceoladas, levemente denteadas nas margens, vermelhas; flores estaminadas ca. $2,5 \mathrm{~mm}$ compr., sépalas 5 , obovais, agudas, amarelas; disco com 5 glândulas pateliformes; estames 3, filetes unidos, tecas convergentes com valvas assimétricas, rimas oblíquas; flores pistiladas ca. $3 \mathrm{~mm}$ compr., sépalas 5, oblongas, agudas, amarelas; disco anular; ovário globoso, amarelo; estiletes 2-partidos, ramos capitados. Fruto cápsula, ca. $3 \mathrm{~mm}$ compr. Sementes castanhas, verruculosas.

Material examinado: BRASIL. Bahia: Abaíra, 25/X/1993, fl., Ganev 2318 (HUEFS); 26/II//1994, fl., Sano et al. CFCR14606 (SPF); 2/III/1992, fl., Stannard et al. 51701 (SPF). Água Quente, 16/XII/1988, fr., Harley et al. 27517 (CEPEC, SPF). Piatã, 3/XI/1996, fl., Bautista 4010 (HUEFS). Rio de Contas, 12/XI/1988, fl., Harley et al. 26418 (CEPEC, SPF); 17/III/1977, fl., Harley 19499 (CEPEC, SPF); 23/I/1974, fl., Harley 15435 (CEPEC); 12/XI/1988, fl., Harley \& Hind 26107 (CEPEC, SPF); 16/X/1987, fl., Harley et al. 25876 (CEPEC, SPF); 23/XI/1988, fl., Harley 26257 (CEPEC, SPF); 14/XII/1984, fl., Stannard et al. 6892 (CEPEC, SPF); 2/III/1999, fr., Melo et al. 2630 (HUEFS).

$P$. spartioides foi coletada florida principalmente nos meses de novembro a fevereiro e com frutos de abril a junho. Até o presente não houve registro desta espécie fora da Chapada Diamantina, sendo possivelmente endêmica desta região.

\section{Phyllanthus sp.}

Fig. 63-67

Subarbustos ca. $40 \mathrm{~cm}$ alt., ramos cilíndricos a levemente achatados não modificados em 


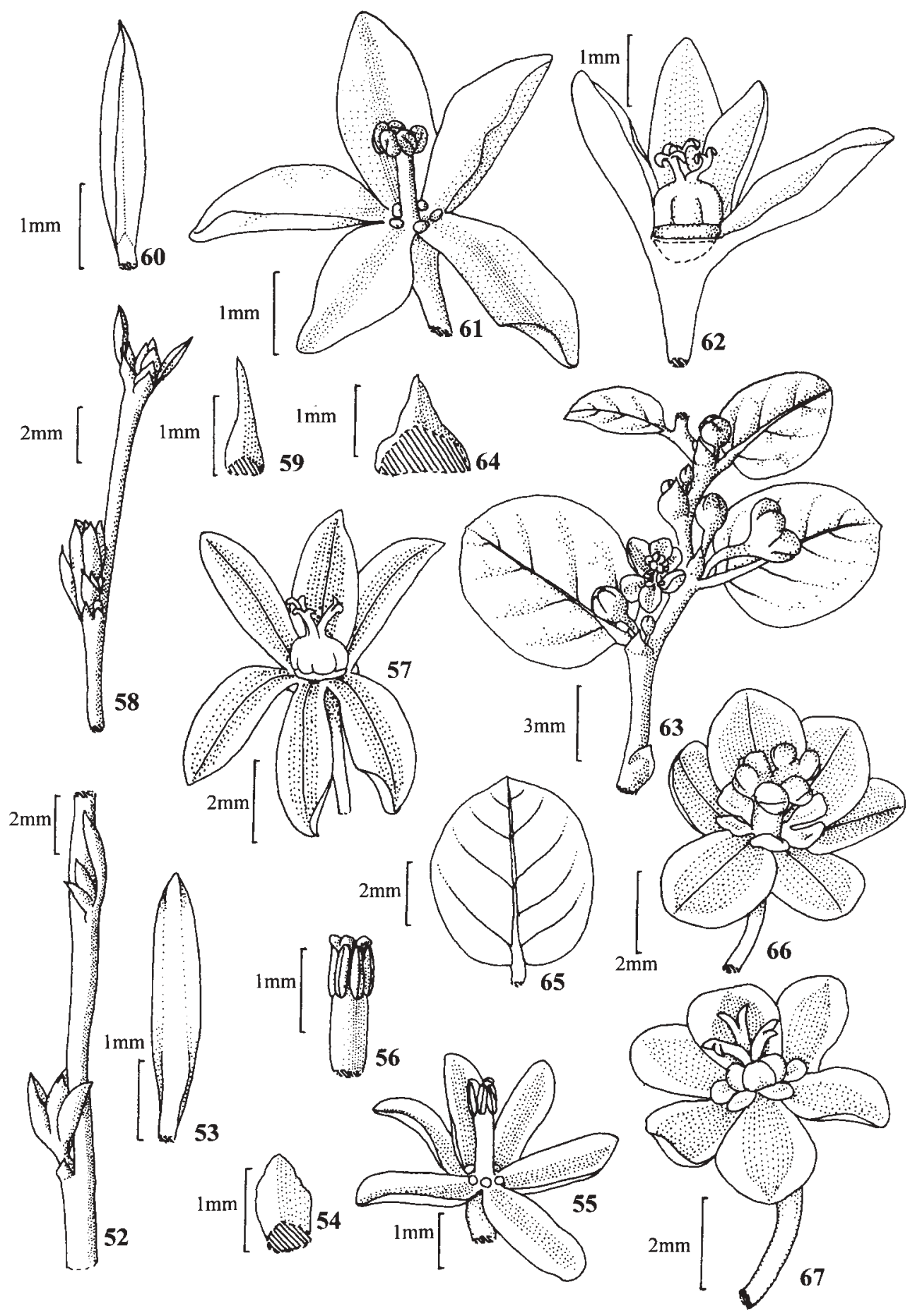

Figuras 52-57. Phyllanthus scoparius Müll. Arg. (Harley 20991). 52. ramo florífero; 53. folha face adaxial; 54. estípula; 55. flor estaminada; 56. detalhe do androceu; 57. flor pistilada. Figuras 58-62. Phyllanthus spartioides Pax \& K. Hoffm. (Ganev 2318). 58. ramo florífero; 59. estípula; 60. folha face adaxial; 61. flor estaminada; 62. flor pistilada. Figuras 6367. Phyllanthus sp. (Queiroz \& Nascimento 4295). 63. ramo florífero; 64. estípula; 65. folha face abaxial; 66. flor estaminada; 67. flor pistilada (Ganev s/n, HUEFS 19189). 
cladódios, glabros, eretos. Estípulas ca. $1 \mathrm{~mm}$ compr., largamente triangulares, agudas. Folhas subcoriáceas, largamente ovais a suborbiculares, 7-12 × 6-11mm, ápice arredondado, mucronulado, base arredondada, margem inteira; pecíolo 1,0-1,5mm compr. Flores em címulas unissexuais, brácteas ca. 1mm compr., triangulares, as inflorescências estaminadas com 2-4 flores, 3,5-5,0mm compr., pedicelo 1,5-2,5mm compr., sépalas 6, largamente elípticas, obtusas, ápice arredondado, margem inteira; disco com 6 glândulas pateliformes; estames 3, filetes unidos, tecas divergentes, rimas horizontais, inflorescências pistiladas com 2-3 flores, 4,5-5,5mm compr., pedicelo 3-4mm compr, sépalas 6, largamente elípticas, obtusas, ápice arredondado, margem inteira; disco com 6 glândulas pateliformes; ovário globoso; estiletes eretos, 2-partidos, ramos agudos. Fruto cápsula, ca. $2,5 \mathrm{~mm}$ compr. Sementes ca. $1,5 \mathrm{~mm}$ compr., castanhas, verruculosas.

Material examinado: BRASIL. Bahia: Morro do Chapéu, 14/III/1995, fl., Queiroz \& Nascimento 4295 (HUEFS). Pindobaçu, 27/X/1993, fl. fr., Ganev s/n (HUEFS19189).

Phyllanthus sp. foi coletada florida e com fruto apenas nos meses de março e outubro. É facilmente distinguível das demais espécies de Phyllanthus da região por apresentar folhas suborbiculares, subcoriáceas, 6 sépalas, 3 estames unidos pelos filetes, flores pistiladas com disco de 6 segmentos pateliformes.

Espécie aparentemente endêmica da Chapada Diamantina. Diferencia-se prontamente das outras espécies de Phyllanthus da região, principalmente por suas folhas subcoriáceas, geralmente suborbiculares, com ápice mucronulado. Além disso, pela posse de um conjunto único de características entre estas espécies: hábito subarbustivo, folhas desenvolvidas, ramificação não filantóide, flores com 6 sépalas, disco segmentado, estames 3, unidos pelos filetes, tecas divergentes, rimas horizontais, estiletes 2-partidos, com ramos agudos.
Pela falta de coleções adicionais, os autores optaram por manter a espécie indeterminada.

\section{Agradecimentos}

Os autores agradecem aos curadores dos herbários citados, pelo empréstimo e envio do material estudado; à Universidade Estadual de Feira de Santana e ao CNPq, pela bolsa concedida à primeira autora; ao professor Dr. Luciano Paganucci de Queiroz, pelas sugestões dadas a este trabalho; a Rogério Lupo, pela arte final das ilustrações.

\section{Referências bibliográficas}

Cordeiro, I. 1992. Flora da Serra do Cipó, Minas Gerais: Euphorbiaceae. Boletim de Botânica da Universidade São Paulo 13: 169-217.

Font Quer, M. P. 1965. Diccionario de Botánica. Editorial Labor S. A., Barcelona.

Harley, R. M. 1995. Introduction. In Stannard, B. L. (ed.) Flora of the Pico das Almas, Chapada Diamantina, Bahia, Brasil. Royal Botanic Gardens, Kew.

Harley, R. M. \& Mayo, S. J. 1980. Toward a checklist of the Flora of Bahia. Royal Botanic Gardens, Kew.

Lorenzi, H. \& Matos, J. A. 2002. Plantas medicinais no Brasil: nativas e exóticas cultivadas. Instituto Plantarum, Nova Odessa.

Mueller, J. 1873. Euphorbiaceae. In: C. F. P. Martius \& A. G. Eichler ed. Flora brasiliensis 11(2):1-752.

Pax, F. \& Hoffmann, K. 1931. Euphorbiaceae. In: A. Engler \& K. Prantl. Natürlichen Pflanzenfamilien $2^{\mathrm{a}}$ ed., 19: 11-23.

Radford, A. E. et al. 1986. Fundamentals of plants systematics. Harper \& Row, New York.

Webster, G. L. 1956. A monographic study of the West Indian species of Phyllanthus L. Journal of the Arnold Arboretum 37(2): 91-122, 217-256, 341-357.

Webster, G. L. 1957. A monographic study of the West Indian species of Phyllanthus L. Journal of the Arnold Arboretum 38: 51-79.

Webster, G. L. 1958. A monographic study of the West Indian species of Phyllanthus L. Journal of the Arnold Arboretum 39: 49-100, 111-212. 
Webster, G. L. 1967. The genera of the Euphorbiaceae in the Southeastern United States. Journal of the Arnold Arboretum 48(3):303-361, 48(4): 363-430.

Webster, G. L. 1970. A Revision of Phyllanthus (Euphorbiaceae) in the Continental United States. Brittonia 22: 44-76.
Webster, G. L. 1994. Systematics of the Euphorbiaceae. Annals of the Missouri Botanical Garden 81: 1-144.

Webster, G. L. 2002. A synopsis of the brasilian taxa of Phyllanthus section Phyllanthus (Euphorbiaceae). Lundellia 5: 1-26. 